\title{
Methane produced by corn stalk anaerobic fermentation under different dosage of $\mathrm{NaOH}$
}

\author{
Yan ZHU ${ }^{1, a}$, Shaojun $\mathrm{LI}^{1, b}$,Shuai YUAN, ${ }^{2, c}$ Guang YUAN ${ }^{1, d}$ \\ ${ }^{1}$ College of Environment and Chemical Engineering,Xi'an Polytechnic University \\ Xi'an 710048, China \\ 2 Department of Material Science and Engineering, Zhejiang University \\ Hangzhou 310027, China \\ a zhuyan_1963@126.com , bj sjl@xpu.edu.cn, c shuaiyuan0821@zju.edu.cn, ${ }^{\text {d}} 939358037 @ q q . c o m$ \\ Keywords: Dosage of $\mathrm{NaOH}$, methane,corn stalk , anaerobic fermentation \\ Abstract With crisis of coal, oil and natural gas and other fossil energy, people gradually turned to \\ biomass energy, the preparation of methane is of great practical significance. Different alkali \\ pretreatment can affect the anaerobic fermentation of corn stalk system. $\mathrm{NaOH}$ as pretreatment agent \\ was added into corn straw in different dosage and different organic loading rate. The corn straws were \\ dealed with $\mathrm{NaOH}$ at different dosage. The results are shown as follows: Compared with corn straw \\ without $\mathrm{NaOH}$ pretreatment,gas amount per day, the cumulative gas amount and the amount of \\ methane has greatly improved, where optimum pretreatment agent was $2 \% \mathrm{NaOH}$.
}

\section{Introduction}

Methane is a clean energy, the most important is that methane can be preparated artificially. So in the face of world energy shortage, people have put methane as an important energy [1]. In 1936 it was initially set up two stage theory of biogas fermentation of acidogenic phase and acid decomposition of methane [2]. In 1950, Hung ate R.E.[3] established the anaerobic technology, and solves the separation and culture of methanogens, established the method of anaerobic fermentation preparation of methane. In 1967, M.P.Bryant[4] further optimize the method of Hungate, namely methane bacteria was separated and purified by using this method. The principle of methanogenic bacteria was revealed. A great contribution to anaerobic fermentation preparation of methane. From 70 s, the research of biomass energy in many countries around the world have launched on and good results have been achieved. For example, $16 \%$ of energy demand is supplied by the city's biogas system, which not only did not pollutes the environment but also alleviates the pressure on energy demand in germany; The UK used anaerobic fermentation technology to deal with waste water and garbage. which not only optimizes the urban environment but also gets a large amount of methane. Russia's main focus is on industrial biogas device. So the emergence of methane as an important energy is already an unstoppable trend in the world. China's utilization of methane has been 80 years, which is divided into three periods. The first period is that Mr Luo Guorui run Guorui natural gas company in guangdong province in 1929. The second period, from 1957 to 1978, was a widespread focus on biogas. The third period, from 1978 to now, national leaders put forward to build new rural construction of energy, not only provides the political guarantee to promote the development of biogas, also protected rural energy guarantee in environment at the same time.

Straw is the rest of the grain harvest, including wheat, corn, potato, cotton, sugar cane, etc. China's crop straw resources are very rich, with more than 700 million tons of crop straw every year, equivalent to 70 percent of the biomass of farmland, consisting mainly of wheat straw, corn stalk, rice straw, etc. The structure of corn stalks is complex, consisting mainly of cellulose, hemicellulose and lignin, and contains coarse protein, coarse fat, ash and a small amount of other ingredients, [5]. But the cellulose and hemicellulose are wrapped by complex of lignin and carbohydrate compounds, such a structure is difficult to decompose, limiting the straw stalk transformation and utilization efficiency[6]. 
In this paper corn straw were pretreated with $\mathrm{NaOH}$. Influnce of anaerobic fermentation gas production rate was discussed. The influence of $\mathrm{NaOH}$ dosage as pretreatment agent on Methane output was considered.

\section{Experimental}

\section{Experimental materials}

The corn stalks used in this experiment were grown from northern shaanxi farmers. First corn stalk was washed by water repeatedlying and then dryed to constant weight in $60{ }^{\circ} \mathrm{C}$ drying oven.

\section{Experimental apparatus}

Screen type pulverizer, Jiangsu hongda machinery co. LTD. Electronic balance, Shanghai precision science instruments co. LTD. Constant temperature water bath, syc-15, Shanghai pudong physical and optical instrument factory. pH meter, JENCO 6173. Vacuum drying oven, Beijing kowei yongxing instrument co. LTD. ZK-40ASB Centrifuge, Changzhou guohua electric appliance co. LTD. Hair dryer, Panasonic TURBODRY EH5262. Nitrogen-fixing apparatus, KDY-9820. Organic carbon analyzer, U.S Dorman co. LTD. Apollo9000. Cellulose tester, Beijing laiheng science and trade co. LTD. 1-807. Meteorological chromatograph, American Agilent4890D. Fourier transform infrared spectra, US Nicolet 5700 intelligent. XRD analyzer, Netherlands X - Pert MPD PRO

\section{Result and Discuss}

As shown in fig.1, we can clearly see the influence of $\mathrm{NaOH}$ dosage on the anaerobic fermentation of corn straw.

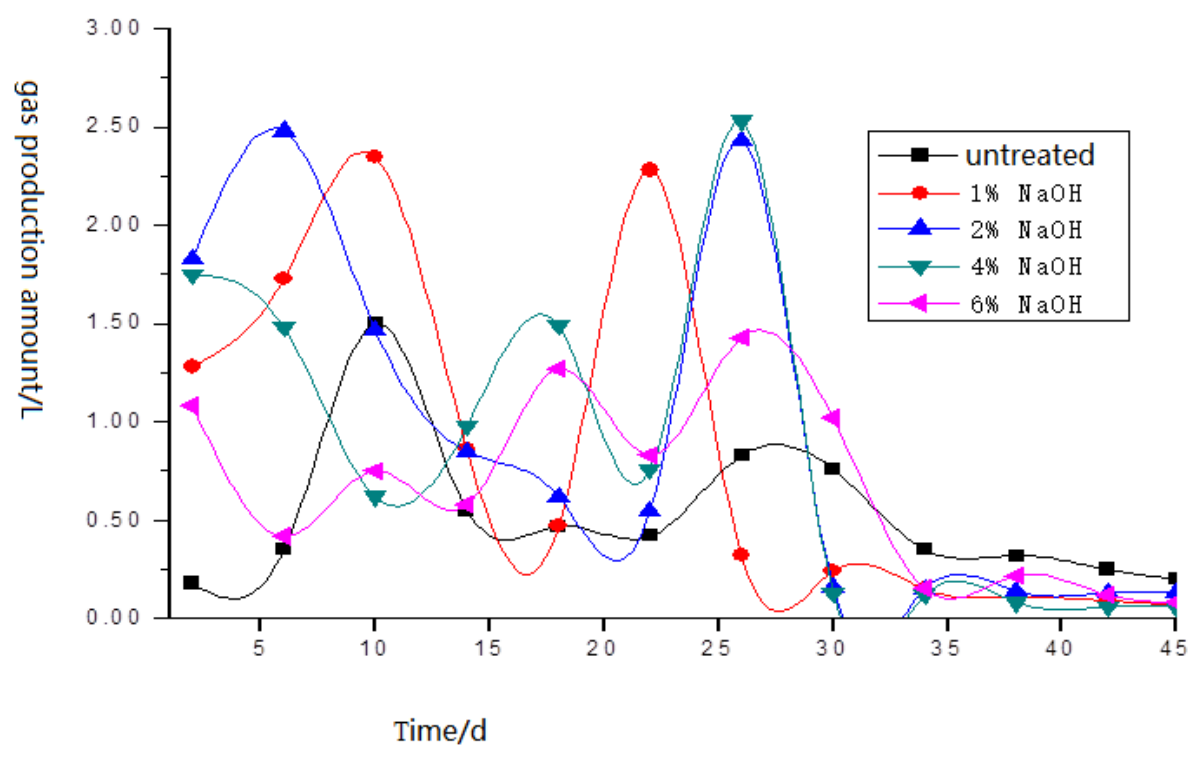

Fig. 1 daily gas production influence of $\mathrm{NaOH}$ dosage on the anaerobic fermentation of corn straw.

We first compare daily gas production on the anaerobic fermentation of corn straw at different $\mathrm{NaOH}$ dosage. At the start of anaerobic fermentation, gas production of untreated corn straw is very low. Gas production increases as the anaerobic fermentation proceeded. Peak of curve appears in the tenth day, the highest gas production volume is $1.5 \mathrm{~L}$, in contrast, gas production rate is high from the anaerobic fermentation beginning stage when different dosage of $\mathrm{NaOH}$ pretreated corn stalk. Wave peak appeared earlier and higher. Time interval between the two peaks is short.

We can compare daily gas amount when corn straw anaerobic fermentation was carried out by different concentration of $\mathrm{NaOH}$. At anaerobic fermentation starting stage, the change of gas amount was successively $2 \mathrm{NaOH} \%, 4 \mathrm{NaOH} \%, 1 \% \mathrm{NaOH}, 6 \mathrm{NaOH} \%$, where highest gas amount were at $2 \% \mathrm{NaOH}$ and $4 \% \mathrm{NaOH}$. The gas amount was significantly higher than that of $1 \% \mathrm{NaOH}$ and $6 \%$ 
$\mathrm{NaOH}$, the highest daily production of gas is about $2.53 \mathrm{~L}$, but the $2 \% \mathrm{NaOH}$ peak appear earlier. With anaerobic fermentation, gas production will stop after 33 days.

From this we can see that compared with the untreated corn stover, the gas production of corn straw pretreated is higher, gas production peak appear early, peak interval is short. All show that gas production is greatly improved after the pretreatment of corn straw.

Fig.2 gave cumulative gas production of anaerobic fermentation of corn stalk under different dosage of $\mathrm{NaOH}$, from the figure we can clearly see that the effect of $\mathrm{NaOH}$ concentration on anaerobic fermentation of corn stalk gas production.

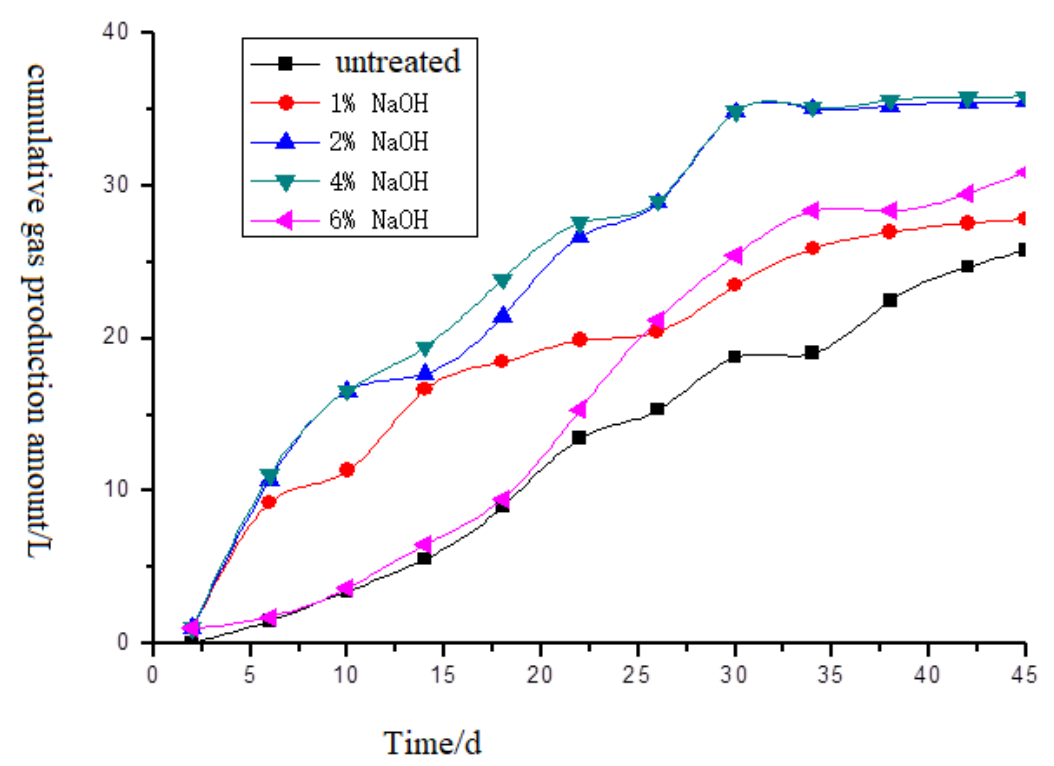

Fig. 2 cumulative gas production of anaerobic fermentation of corn stalk under different dosage of $\mathrm{NaOH}$

From Fig.2, We can see that cumulative gas production growth trend of both untreated corn straw and corn stalk with $\mathrm{NaOH}$ pretreatment is the same. Cumulative gas amount decreased in turn from 4 $\%$ of $\mathrm{NaOH}, 2 \% \mathrm{NaOH}, 1 \% \mathrm{NaOH}, 6 \% \mathrm{NaOH}$ and untreated. When $\mathrm{NaOH}$ dosage is $4 \%$ and 2 $\%$, cumulative gas amount of $\mathrm{NaOH}$ was obviously higher than that of the other three groups, and there was no evident difference between them. The cumulative gas production of untreated corn stalks is lowest and the growth rate was slow and the cumulative gas production of the pretreated corn stalks is higher and the growth rate was faster but it were basically stable after 33 days.

By comparing the cumulative gas production of different dosage of $\mathrm{NaOH}$, we learn that the cumulative gas production is not proportional to the amount of $\mathrm{NaOH}$, such as accumulative gas production of $2 \% \mathrm{NaOH}$ is $35.48 \mathrm{~L}$, accumulative gas production of $1 \%$ of $\mathrm{NaOH}$ is $27.78 \mathrm{~L}$, cumulative gas production of $\mathrm{NaOH}$ is $30.85 \mathrm{~L}$, it shows $\mathrm{NaOH}$ dosage must be appropriate. If it is too little, it don't take part in anything. If $\mathrm{NaOH}^{\prime}$ s dosage is excessive, it played an inhibitory effect.

Corn stalk anaerobic fermentation produces a mixture of water vapor, hydrogen sulfide, carbon monoxide, oxygen, nitrogen, hydrogen, etc. The main compositions are methane and carbon dioxide. Methane as the goal production of this experiment, so the determination of methane content is particularly important, the corn straw anaerobic fermentation under different dosage of $\mathrm{NaOH}$ as shown in figure 3 , we can see clearly how the dosage of $\mathrm{NaOH}$ influenced corn straw anaerobic fermentation and methane content. 


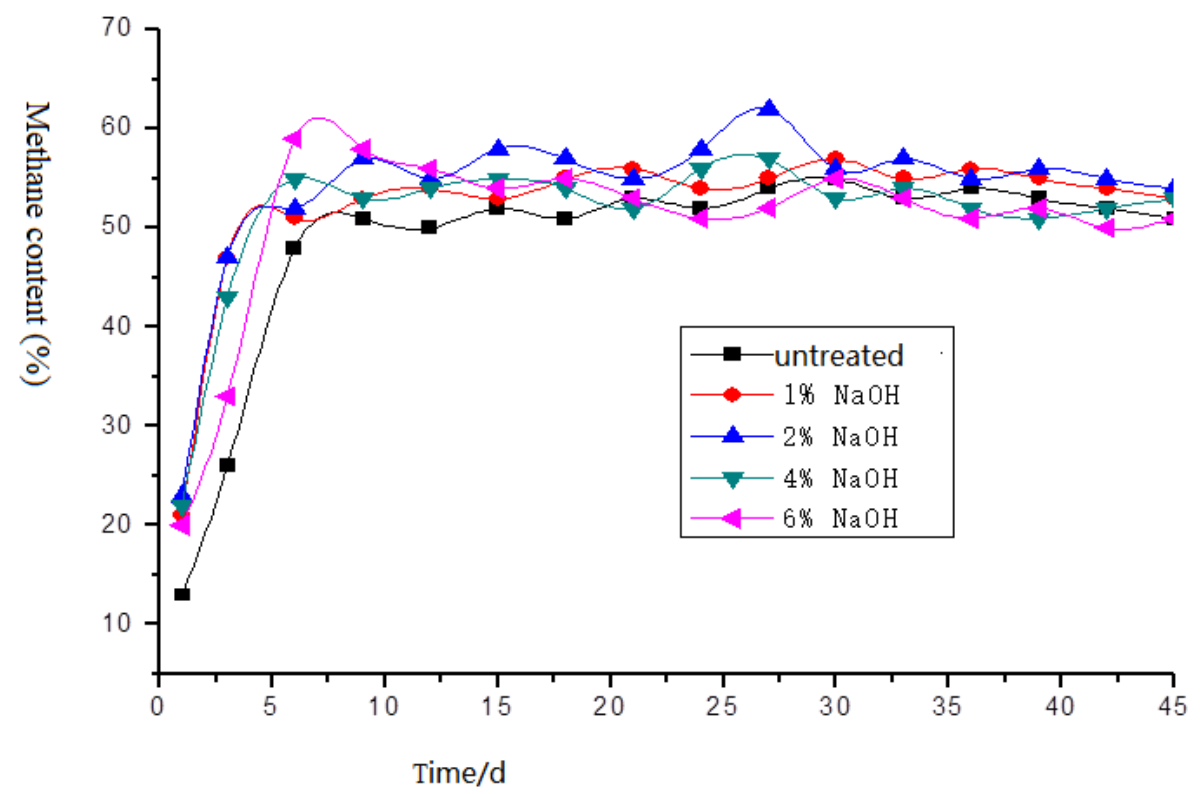

Fig.3 Methane content change with anaerobic fermentation of corn stalk under different dosage of $\mathrm{NaOH}$

Methane content unprocessed and pretreatment of corn straw anaerobic fermentation are low at the start stage and rise rapidly later. Finally tend to be stable and have the same change trend. But unprocessed methane content has been lower than pretreatment one on the whole.

\section{Conclusion}

Methane content of corn straw anaerobic fermentation changed with different $\mathrm{NaOH}$ dosage. Methane content of corn straw anaerobic fermentation dealed with $2 \% \mathrm{NaOH}$ reached $50 \%$ in 3 days ,then changed between $50 \% \sim 65 \%$. Methane content of corn straw anaerobic fermentation dealed with $1 \%, 4 \%, 6 \% \mathrm{NaOH}$ reached $50 \%$ in 6-7 days, then changed between $50 \% \sim 65 \%$. So methane content of corn straw dealed with $2 \% \mathrm{NaOH}$ entered stable state in advance than other system.

\section{Acknowledgment}

This research was financially supported by the National Science Foundation, Textile guidance plan term , Science and Technology Foundation of Shanxi.

\section{References}

[1] Putun A E; Apaydm E; Putun E Rice-straw as a bio-oil source via pyrolysis and steam pyrolysis [J] 2004(12-15)

[2] Ghosh A,Bhattacharyya B C. Biomethanation of white rotted and brown rotted rice straw[J]. Bioprocess Engineering,1999,20: 97-302.

[3] Hung ate R. E. Atoll tube method for cultivation of strict anaerobes[J] . Method in Microbial,1969,38: 117-132.

[4] Bryant M. P. Microbial methane production-theoretical aspects[J]. Animal science,1979,

[5] Yang, Jinhai; Structure and physical properties of cellulose acetate/poly (L-lactide) blends[J]. Journal of Applied Polymer Science,2002,85 (6):1219-1226. 
[6] Wang, Xiaojun; Effect of microwave irradiation on the physical properties and morphological structures of cotton cellulose [J]. Carbohydrate Polymers,2008,74(4):934-937. 